NBER WORKING PAPER SERIES

\title{
CAN PUBLIC DISCUSSION ENHANCE PROGRAM OWNERSHIP?
}

\author{
Allan Drazen \\ Peter Isard \\ Working Paper 10927 \\ http://www.nber.org/papers/w10927 \\ NATIONAL BUREAU OF ECONOMIC RESEARCH \\ 1050 Massachusetts Avenue \\ Cambridge, MA 02138 \\ November 2004
}

\begin{abstract}
Allan Drazen holds the Jack and Lisa Yael Chair in Comparative Economics at Tel Aviv University and is Professor of Economics at the University of Maryland. This is a revised version of a paper prepared for the IMF Conference in Honor of Guillermo Calvo, Washington, DC, April 15-16, 2004; it will be published in the forthcoming conference volume. We thank our discussant Raquel Fernandez, as well as Jim Boughton, Eddie Dekel, Thomas Dorsey Marcela Eslava, Judith Gold, Caroline Kende-Robb, and Nuno Limão for helpful comments and discussions. Parts of this paper were written while the first author was visiting the IMF, which he thanks for its hospitality. The views expressed herein are those of the author(s) and do not necessarily reflect the views of the National Bureau of Economic Research or the International Monetary Fund.
\end{abstract}

(C) 2004 by Allan Drazen and Peter Isard. All rights reserved. Short sections of text, not to exceed two paragraphs, may be quoted without explicit permission provided that full credit, including $\odot$ notice, is given to the source. 
Can Public Discussion Enhance Program Ownership?

Allan Drazen and Peter Isard

NBER Working Paper No. 10927

November 2004

JEL No. D72, D74, F34

\begin{abstract}
We use the concepts of deliberative democracy from political science and cheap talk from economics to develop a better understanding of how public discussion can contribute to building and demonstrating ownership of IMF programs and hence to program success. We argue that ownership is more complex than many discussions of it would suggest, since it must include not only the willingness to carry out a program, but also the technical capacity and especially the political ability to do so. Public discussion can serve a number of purposes, each of which can be better understood by moving to a more formal treatment. We illustrate our points by means of simple examples. We also consider some of the drawbacks of public discussion, especially as applied to IMF programs.
\end{abstract}

\author{
Allan Drazen \\ Department of Economics \\ University fo Maryland \\ College Park, MD 20742 \\ and NBER \\ drazen@econ.umd.edu \\ Peter Isard \\ IMF Institute \\ International Monetary Fund \\ $70019^{\text {th }}$ Street, NW \\ Washington, DC 20431 \\ pisard@imf.org
}




\section{INTRODUCTION}

IMF-supported programs have a mixed record of success. A significant share of programs fail to reach their originally scheduled "completion dates," many others require substantial modifications along the way, ${ }^{2}$ and many countries remain under IMF-supported programs for prolonged periods of time. ${ }^{3}$

An often-cited reason that IMF-supported programs get off track is a lack of ownership on the part of the program country, where ownership refers loosely to the extent to which a country is "committed" to the general reform process and the conditions specified by the program independently of the incentives provided by multilateral institutions. Genuine ownership on the part of a country, combined with sufficient lending from the IMF and good program design, is believed to yield program success (or at least a high probability of success). And indeed, when the IMF refers to ownership it defines the concept in a circular way, based implicitly on the vision of reaching program completion dates: "National ownership refers to a willing assumption of responsibility for a program of policies, by country officials who have the responsibility to formulate and carry out those policies, based on an understanding that the program is achievable and is in the country's best interest."

The main challenges that arise in wrestling with the concept of ownership do not stem primarily from disagreement over the most appropriate definition, but rather reflect the difficulties of making the concept of ownership operational. ${ }^{5}$ How can the IMF determine whether a country is likely to remain committed to the reform effort and comply with the conditions of its program through the completion date? And how can the IMF design programs to enhance the prospect that countries will remain committed and completion dates will be reached? These questions identify and distinguish between two central issues: demonstrating that ownership is present and building or creating ownership when it is thought to be weak. The former issue is perhaps most relevant for countries that have failed

\footnotetext{
${ }^{2}$ For readers unfamiliar with IMF jargon, the term "completion date" refers to the date at which the borrowing country becomes eligible for the last installment of the IMF loan, based on demonstrated compliance with, or agreed waivers or modifications of, the performance criteria and other conditions of the program. Out of the 615 IMF-supported programs approved between 1973 and 1997, only 70 percent achieved their originally agreed "completion dates" (in many cases with modifications along the way); an additional 12 percent were extended beyond their original durations; another 11 percent were canceled early but were followed promptly by successor arrangements; and 7 percent were effectively suspended. See Mussa and Savastano (2000).

${ }^{3}$ Under a definition that treats a country as a prolonged user of IMF resources if it has had IMF-supported programs for 7 or more years within a 10-year period, 44 countries were prolonged users during some part of the 1971-2000 period; see Independent Evaluation Office (2002).

${ }^{4}$ IMF (2002).

${ }^{5}$ See Boughton and Mourmouras (2002).
} 
to comply with the conditions of programs in the past and must demonstrate that, contrary to perceptions based on past performance, they are now truly interested in and committed to reform. ${ }^{6}$ The latter issue recognizes that ownership is endogenous, not an innate or exogenous characteristic. Ownership can be improved and fostered through various devices. That is why we argue that a key challenge that a reform-minded government faces is building ownership - that is, creating support for the process of reform and for the specific measures embodied in an IMF-supported program.

Among the general public and especially critics of the IMF (and the World Bank), the lack of ownership and the failures of IMF-supported programs are often attributed to a lack of public discussion of the programs during the formulation stages. Our use of the term "public discussion" in this paper refers broadly to mechanisms through which policymakers disseminate and exchange information with the public, including discussions both to formulate programs and to explain program design. It appears to be similar to what others have called "participation" in the recent literature on economic development and poverty and social impact analysis.

Critics of the IMF often characterize the process of formulating a program as one of negotiations between the IMF (seen as having its own agenda) and a thin layer of high-level government officials, with little or no input from the public, from NGOs, or from other interested parties. The failure of a program to lead to a significant bettering of the economic condition of the general population is often seen as reflecting this lack of public input. Demonstrations (or riots) against the IMF and the programs it supports are taken as evidence of the seriousness of the problem. Public discussion is considered to be an important vehicle for establishing ownership, and lack of public discussion is perceived as part of the reason that some programs are never adopted or fail to reach completion.

The need for public discussion is recognized within the IMF and World Bank. ${ }^{7}$ To date, however, the case for public discussion is not much more developed than the cases for other terms that sound unambiguously positive. In particular, the discussion of "public discussion" seems quite unfocused and lacking in coherent analysis of what form it should take and how it can contribute to strengthening IMF-supported programs and/or demonstrating or building ownership. Such lack of careful, analytic argument on the role of public discussion can leave the unfavorable impression that the IMF and World Bank simply view public discussion as "politically correct" rather than as a vehicle that can significantly improve program design - or that they engage in public discussion primarily to make the public feel "more comfortable with" or "warm and fuzzy about" their programs. A more serious concern is that the lack of a clear understanding of how public discussion works can leave the impression that public discussion "strengthens" ownership only by leading counterproductively to the adoption of weaker programs. At worst, public discussion is seen

\footnotetext{
${ }^{6}$ It is not only to the IMF that ownership must be demonstrated. Demonstration of ownership may also have a "catalytic" effect in inducing both official bilateral lending and private capital flows that exceed or add substantially to official multilateral loans.

${ }^{7}$ See, for example, IMF (2003a), paragraph 7.
} 
as making strong program design very difficult or impossible by giving too much voice to groups that are either against real reform or hold views strongly at odds with generally accepted economic wisdom. Thus, it is not surprising that public discussion has a bad name in some circles, at least when it is not discussed publicly.

Both the association of public discussion with fuzzy thinking and the view that it detracts from successful program design are especially unfortunate. In our view, careful public discussion of programs can increase necessary public support and in any case is often unavoidable. The purpose of this paper is to distinguish a number of different functions that public discussion can serve and to illustrate its potential for improving collective choice.

The paper does not break new theoretical ground, but it uses the tools of economic theory and political science to help develop a better understanding of how public discussion can contribute to building and demonstrating ownership. The first task is to develop a better understanding of both ownership and public discussion. In Section II, we argue that ownership is more complex than many discussions of it would suggest. Ownership must include not only willingness but also technical capacity and political ability to carry out a program, especially the political ability to do so. In Section III, we argue that public discussion can serve a number of purposes - including educating the public, revealing public preferences and constraints (or educating policymakers), demonstrating the unbiasedness of policymakers, finding common ground among heterogeneous interests - each of which can be better understood by moving to a more formal treatment. What public discussion can or cannot achieve depends on what the ownership problem is, and the different purposes of public discussion may interact with one another. Here too, understanding the political constraints on a government may help one to understand what to expect from public discussion. In Section IV, we illustrate our arguments using simple examples relevant to actual program design. In Section $\mathrm{V}$ we consider some of the drawbacks of public discussion, especially as applied to IMF-supported programs.

After having developed a clearer sense of ownership and a more formal understanding of what public discussion can achieve in different types of circumstances, we focus in Section VI on the design of IMF-supported programs and the role that public discussion can play in enhancing program ownership. We argue that the difficulties of attaining program ownership depend on the nature of the conditions involved, that this should be taken into account in designing programs and seeking to build overall program ownership, and that the recent emphasis on streamlining IMF conditionality can be counterproductive if it results in the elimination of conditions for which ownership is potentially very high. We also suggest that the effectiveness of both IMF-supported programs and the IMF's surveillance of nonprogram countries might be enhanced through more explicit focus ex ante on the obstacles to building ownership for policies and programs and on how those obstacles can be overcome or mitigated through public discussion. Section VII provides a summary of our arguments and conclusions.

\section{DEFINING OWNERSHIP}

Ownership is a more complex concept than it may seem. As noted above, the degree to which a country "owns" an IMF-supported program can be broadly defined as the extent 
to which the country is oriented toward meeting the conditions specified by the program independently of any incentives provided by multilateral lenders. Alternatively, and from the perspective of seeking to draw meaningful implications for the design of IMF-supported programs and the role of public discussion, the degree of ownership can be defined as the probability that an IMF-supported program will be adopted and reach completion without a significant weakening of the reform effort.

The latter definition points to a number of factors on which ownership depends. One is the willingness of the government to meet the conditions of the program. Without such willingness, the probability of reaching completion is unlikely to be high. Suppose, however, that there is willingness but a lack of technical capacity to collect taxes or carry out other measures on which the program crucially depends. ("The spirit is willing, but the infrastructure is weak.") It would not seem meaningful to suggest that a country owns a program that it has no hope of carrying out: ownership also depends on technical capacity. Conversely, ownership for its own sake is not a desirable objective. Just as it is not very meaningful to design diets that overweight individuals are willing and able to undertake because they require only minimal changes in eating habits, it would not be very desirable to design programs that countries are willing and technically able to carry out simply because they require only minimal changes in policy.

A third crucial factor for ownership is the political ability of the government to carry out a meaningful program. To illustrate the point, suppose policymakers in a country with continuing large fiscal deficits want to implement a program of fiscal austerity but face powerful special interest groups (SIGs), either inside or outside government, who can block fiscal reform. One could not argue that there is country ownership if the SIGs do not agree to the fiscal austerity program, even if the government is willing and technically able to carry out the program. ${ }^{8}$ The same argument suggests that ownership can be strengthened by weakening either the power or the incentives of SIGs to block the program. The nature of the political system can very much determine the power of SIGs, while both the design and public discussion of programs can affect their incentives. We return to the latter point in our analysis of how public discussion can affect ownership.

Willingness, technical capacity, and political ability are not independent of each other as determinants of program ownership. The distinction between the willingness of the government to carry out reforms and its political ability to do so is often unclear, as is the distinction between its technical capacity and its political ability to collect taxes or discipline public spending. In some cases, distinguishing between technical and political capacity may be unimportant or irrelevant. One may want to think simply of "institutional capacity," broadly defined to reflect the technical characteristics of fiscal processes as well as the nature of the political institutions that influence what comes out of fiscal processes.

\footnotetext{
${ }^{8}$ This distinction between country and government (or authority) ownership is central to the arguments on conditionality presented in Drazen (2002) and is explored in detail there.
} 
The IMF is unlikely to find itself involved in a program in which country ownership is ex ante complete. Were ownership complete - that is, if a country had the willingness, technical capacity, and political ability to pursue serious reforms - it would not have to approach the IMF for support. ${ }^{9}$ In this sense, the challenge faced by the IMF in negotiating and designing programs - and in considering how to make effective use of public discussion - is not simply to try to determine the degree of ownership but also to try to increase - that is, to build and strengthen-ownership. This leads to the question of the role of public discussion in designing effective programs and especially in enhancing ownership.

\section{A Framework for Understanding the Role of Public Discussion}

Public discussion has an image problem: calls for public discussion are often perceived to be based primarily on the desire to increase ownership by making the public feel "more comfortable" about a program in some general way. Our aim in this paper is to move away from the "warm and fuzzy" and try to analyze public discussion more rigorously.

From a more analytical perspective, public discussion of a program may be seen as having a number of functions, which may be grouped into four categories:

- $\quad$ to educate the public about the nature of the program and, more generally, about macroeconomic realities, including the trade-offs between short-run costs and medium-run benefits and the implications of the program for relevant interest groups. It can also provide a vehicle for the government (and/or the IMF) to make the public aware of information on which the program is based;

- $\quad$ to learn public preferences and constraints, and to convince the public that program design takes this information into account, which (along with educating the public) may enhance compliance and cooperation with the program;

- to demonstrate unbiasedness - that is, to convince the public that the program is designed for the general good, rather than to serve the interests of the authorities or the IMF; and

- $\quad$ to find common ground among heterogeneous interests.

"Public discussion" might appear to be a topic not easily formalized and discussed with any rigor. However, there are two highly relevant strands of literature-one in economics, the other in political science - that are rigorous and, we believe, potentially quite relevant for developing a more concrete awareness of the different ways that public discussion can effect policy outcomes. As discussed below, the economics literature on

${ }^{9}$ IMF involvement might be crucial in inducing complete country ownership (as in the use of conditionality in Drazen [2002]), so that one could observe IMF-supported programs where country ownership appears to be complete (ex post). 
"cheap talk" is useful for illustrating how discussion can help country governments and/or the IMF to learn about preferences and constraints, demonstrate their unbiasedness, or find common ground among different interest groups. And the political theory literature on deliberative democracy is helpful in thinking about the educational role of public discussion.

\section{A. Cheap talk}

Economic theory distinguishes between costly signaling mechanisms and "cheap talk," where the latter is defined as a signal that an agent can send that is neither costly nor binding and that does not directly affect the payoffs associated with any given outcome. ${ }^{10}$ As an example of costly signaling, suppose that two jobs require different levels of ability, but that individual ability is unobserved. If innately high-ability individuals find it less costly to become educated than do low-ability individuals, observable educational attainment may serve as a signal of unobserved ability. The signal works because it is differentially costly for different types of individuals to send it.

Suppose, however, that individuals simply announce to employers what their ability is, with it being costless for an individual to make any announcement he wants (hence, the term cheap talk). One might think that such costless signals are completely uninformative. However, under certain conditions cheap talk can in fact convey information about unobserved characteristics. Cheap public discussion may enable the government to convey information that its objective is maximizing social welfare (rather than having its own agenda); and cheap talk may enable the public to convey information about its preferences to those who design programs. We return below to this application of public discussion.

Cheap talk may also be a useful coordination mechanism - that is, a device for finding common ground. The challenge of program design presents the government not only with the difficulties of convincing the populace of its good intentions, but also with the need to forge an agreement among different special interest groups. We also consider how public discussion applies to the latter task.

Note that in considering the importance of "talking" we have not made any reference to bargaining or negotiations per se. The issue of how bargaining affects outcomes can, of course, be analyzed formally, but that is not our intention in studying public discussion.

\section{B. Deliberative democracy}

Political science has generated quite a bit of literature on communication between political leaders and the public, and on the role of such communication in shaping policy decisions and generating support for policies and political leaders. Much of this literature is empirical or illustrative, arguing the importance of communication yet not providing a theoretical or formal way to understand why public discussion may be important.

${ }^{10}$ Farrell and Rabin (1996) present an excellent, easily accessible introduction to the subject. 
There is, however, a rigorous strand of literature that focuses on why public discussion may be important in a democracy (Elster, 1998a). ${ }^{11}$ This is the analysis of "deliberative democracy," which can be roughly defined as "decision making by discussion among free and equal citizens" (Elster, 1998b, p. 1), with the stress on "discussion." According to this literature, a crucial part of the democratic process is discussion and deliberation before a collective choice is made. The central question in assessing discussion is put clearly by Fearon (1998):

What good reasons might a group of people have for discussing matters before making some collective decision, rather than simply voting on the issue or using some other decision rule that does not involve discussion? In other words, what is the point or value of discussing things before making political decisions? (p. 44, italics in original)

Advocates of deliberative democracy argue that decision making in a democracy is not simply the aggregation of (existing) policy preferences among heterogeneous agents in a society. That is, it is not simply a collective choice rule (such as majority voting) for reaching an aggregate policy decision when individual citizens do not agree on their most preferred policy. Instead, and perhaps more important, democratic decision making involves the transformation of individual preferences through deliberation and discussion (Habermas, 1987). ${ }^{12}$ In common parlance, if two individuals have different opinions, the free and open discussion of issues that is part of the democratic process enables each side to attempt to convince the other of the correctness of its own position. Thus, discussion provides a mechanism for trying to narrow differences of opinion. In the limit, deliberation and discussion would bring about a consensus of opinion, so there would be no need to use voting or some other mechanism to aggregate preferences.

In applying this perspective to IMF-supported programs, the relevant question is: how can public discussion lead to a consensus, or at least a narrowing of differences of opinion, on what policy should be followed? It is crucial to note that the focus here is on policies and not on outcomes. Two constituencies may differ in their desires for narrowing income inequality, for example, as an outcome, or they may agree on the desired degree of income inequality but differ over the best way to achieve it. Hence, their disagreement is not about goals but about the best way to achieve them. ${ }^{13}$ That is, they disagree about the connection between policies and outcomes, or more generally, about how the world works. We term this an issue of "causal policy-to-outcome relations," or simply causal relations.

${ }^{11}$ From a formal point of view, political scientists have also used cheap talk models to study, for example, communication in legislatures.

${ }^{12}$ Some critics argue that this transformation may actually be a distortion of individual preferences. See Section V below.

${ }^{13}$ The reader will probably quickly point out that individuals may view income inequality not as itself the outcome, but rather in terms of its effect on other variables, such as growth. That is, individuals may favor high growth but differ on the connection between income inequality and growth. For illustration, see the discussion in Chapter 11 of Drazen (2000). 
We note this point because - in the context of IMF-supported programs - the possibility of educating the public about the effects of policies is a key consideration. That is, public discussion can make the public aware of the "payoff matrix" they face and thus perhaps lead them to choose to comply with the proposed program (to choose "ownership") as leading to better outcomes for all parties than the outcomes associated with noncompliance.

In addition to the positive question of whether deliberation can lead to ownership, there is a normative question of whether deliberation leads to welfare-improving outcomes. As already mentioned in the introduction, some observers stress the possible negative implications, a point we consider in detail in Section V.

\section{Voting versus program design}

Many discussions of deliberative democracy focus on the role of public discussion prior to voting on policy. By contrast, we are interested in the value of public discussion of policy proposals before a government commits to a policy program with the IMF.

That public discussion is followed by the government adopting a program, rather than voting, is a key distinction between our framework and most applications in the political theory literature. This difference may have implications for the functions of public discussion as well as for the pathologies (i.e., circumstances in which public discussion may be counterproductive). A second factor that distinguishes our framework, and that may influence the relative importance of various arguments, is that IMF-supported programsespecially difficult ones that need the most public discussion - are typically designed when the economic outlook is particularly bad. As we shall see, these features of our framework introduce some considerations not present in a voting setup.

\section{Illustrating the Functions of Public Discussion}

Public discussion is a vehicle for transmitting information. This includes both economic information about the state of the economy and the links between policies and economic outcomes and socio-political information about the preferences and agendas of the government, relevant national constituencies, or the IMF itself. This section focuses on how the design and ownership of programs can be strengthened by the transmission of such information. Our purpose is not to break new theoretical ground, but to illustrate these points by means of simple examples as applied to actual IMF-supported programs.

In analyzing the various functions that public discussion may serve, it is useful to address three separate questions sequentially. First, as a reference case, what are the functions of public discussion when the government is known to maximize social welfare (rather than being thought to have its own "agenda") and the public is homogeneous (rather than having heterogeneous interests)? Second, how can public discussion help in convincing the public that the government's objective is in fact maximization of social welfare (thus presumably increasing public support and compliance)? Third, what additional functions 
might public discussion have in addressing the conflicting (heterogeneous) interests of groups in society?

Throughout this section we restrict attention to communication between two parties, focusing on communication either between the government and the public or between two interest groups. We assume that the IMF's objectives coincide with those of the government. ${ }^{14}$ This assumption implies that the argument that the IMF's interests do not coincide with those of countries entering programs can be captured by Case 2 below on the role of public discussion when the authorities in a country may not be acting in the interests of social welfare.

\section{A. Case 1: Government known to maximize the social welfare of a homogeneous public}

Consider first the case where it is common knowledge that the government's objective is maximization of social welfare and the public is homogeneous in its preferences and beliefs. ${ }^{15}$ These two assumptions are admittedly extreme and unrealistic, but this case is useful in understanding the importance of public uncertainty about the government's objectives and of heterogeneity in agents' objectives.

In this reference case we ask: since the public knows that the government is maximizing its welfare, why isn't it effective for the government simply to announce its program without any prior discussion? Our answer is that the achievement of the optimal outcome may depend on a number of functions that public discussion can serve: (i) revealing the public's preferences; (ii) convincing the public that the government is aware of what it values; (iii) educating the public; (iv) revealing information about available resources and/or efficient choices; and (v) making the government's commitment to a program more credible.

When the government has imperfect information about what the public wants, public discussion can serve the function of revealing information. This can be a serious problem when program negotiation involves only the IMF and a "thin layer" of high government officials. Since preferences are necessarily complex, it can be argued that the government and the IMF cannot possibly design a program that is socially optimal (or perceived as such) without consulting the public. In comparison with other ways of forming judgments about ownership, public discussion has the attraction of being a relatively quick and resourceefficient way to seek feedback. ${ }^{16}$

${ }^{14}$ Financial constraints on the IMF, for example, may lead its objectives to differ from those of a country's authorities. See Drazen (2002) for a discussion of some of the issues involved in whether the government and the IMF have the same or different objectives.

15 "Common knowledge" means not only that something is known by all parties, but that everyone knows that everyone knows, everyone knows that everyone knows that everyone knows, etc.

${ }^{16}$ By contrast, the methods that Wimmer, de Soysa, and Wagner (2002) suggest for assessing the feasibility and sustainability of reforms would appear to require considerable resources and time to implement. 
We may illustrate our points in simple matrices of payoffs to the government and a homogeneous public. Consider Matrix 1. (In this case the use of a formal model is perhaps trivial, but it sets the stage for later examples.) Public's type is Left, but Government does not know this. (Formally, the game is either Left or Right, which Public knows but Government does not.) For example, Left means relatively large tax-financed social welfare programs, and Right means relatively small tax-financed social welfare programs. A policy of High (government spending) is optimal when Public prefers Left and a policy of Low (government spending) is optimal when Public prefers Right. (Since Government is known to maximize social welfare, the payoffs are identical to both Public and Government in each cell.) Government must choose the optimal policy, where it does not know what Public wants. In the absence of communication, Government must choose on the basis of its prior beliefs about Public's preferences (where we assume that once Government chooses a policy it cannot change). Suppose Government assigns probability of $1 / 2$ to each possibility (actually, any interior probabilities will suffice for this example), so that the expected payoff is $(2,2)$.

\section{Matrix 1}

\begin{tabular}{|c|c|c|}
\hline \multirow{2}{*}{ Government program } & \multicolumn{2}{|c|}{$\underline{\text { Public }}$} \\
\hline & Left & Right \\
\hline High & 3,3 & 1,1 \\
\hline Low & 1,1 & 3,3 \\
\hline
\end{tabular}

Here, the problem is solved if Public simply announces that it is Left, which it is optimal for it to do. Public discussion increases welfare since it allows the public to credibly signal its preferences even though such discussion is cheap talk. (Formally, Public's preferences are self-signaling. $)^{17}$

A related role for public discussion is to convince the public that the government is really aware of what the public values. This is relevant when the public knows that the government's objective is maximization of social welfare but feels the government may not be aware of society's preferences. This is clearly related to the previous argument, but it is not identical: the previous argument applies when the government does not have information on the public's preferences; the second role recognizes that even a perfectly informed government must sometimes convince people that it is informed. Put another way, in the first

${ }^{17}$ When the public consists of groups with conflicting interests, then public discussion meant to elicit information on preferred policy may not serve the same function, since groups have the incentive to reveal information strategically. We return to this problem in Section IV.C. 
case public discussion is used to shape a program; in the second, to help "sell" a program. Formally, the public's preferences must not simply be known, but must also be common knowledge. This possibility suggests one interpretation of the notion that "people want to be included" in program formulation, in this case, enough so to be convinced that the decisionmaker really does know their preferences. In other words, public discussion may serve to increase the legitimacy of policy.

Another function of public discussion is to address the possibility that the general public knows the government's preferences (or at least knows that the government's objective is maximization of the public's welfare) but is uninformed about "how the world works"- that is, about what we above termed causal relations. ${ }^{18}$ In other words, the function of public discussion is to educate the public about "economic realities." Przeworski (1998), for example, argues that transmitting knowledge about such causal relations is central to what deliberation is supposed to do (p. 144):

The preferences on which people act are contingent on their beliefs about the consequences of their actions. And, indeed, parties and candidates competing for office do not offer merely policies: they explain to the electorate how these policies will affect the outcomes, trying to persuade citizens that their policies, as distinct from those of their opponents, will lead to the outcomes they want.

We may represent this case by making a number of changes to Matrix 1. First, "Left" and "Right" now refer not to the public's type, but to the "state of the world." Second, it is now Government that has superior information - it knows the state of the world and the associated optimal policy, while Public does not. For purposes of the example, let the state be Right, calling for a policy of low government spending. (That is, in the matrix above, the true "game" is only the right-hand column.) Third, a government program can be enacted only if Public favors it. (Hence, it is Public that chooses High or Low.) Finally, Public does not know the true payoffs connected with different policies. As a concrete example, one may think of the state of the world as "overheated," with Public not fully understanding the longer-run effects of countercyclical and procyclical policies. Though the true payoffs are as in Matrix 1, Public believes that the payoffs associated with different policies are as in Matrix 2. In this case, Public would favor high government spending even if Government announced that the state was Right and that announcement was believed. Hence, though Government has superior information, it must convince Public not only about the state of the economy, but also about "what works." Once it does that (that is, once it convinces Public that the payoffs are those in Matrix 1 rather than Matrix 2), then it need simply announce the state of the world, and a policy of low spending would be supported.

${ }^{18}$ Since programs are economically complex, the public will never fully understand all the details. Hence, there must be a degree of "trust" in the government. This can be attained by generating a feeling of inclusion in the process. 


\section{Matrix 2}

State of the world

\section{$\underline{\text { Government program }}$}

Left Right

\begin{tabular}{|c|c|c|}
\hline High & 2,2 & 1,1 \\
\hline Low & $-1,-1$ & $-2,-2$ \\
\hline
\end{tabular}

The "educational" function of public discussion may be especially important in countries where IMF-supported programs have historically been viewed as "bitter pills prescribed by the malevolent international financial community," as represented by the public belief in payoffs being described by Matrix 2. In these cases, public discussion has the potential to help identify the truth by sifting through whatever valid or invalid inferences have been drawn from historical experience.

Educating the public about causal relations may also be important to ensure compliance with a program. A program may be successful only if the public complies with it, which depends on their understanding of why it is beneficial. To illustrate, suppose "Left" and "Right" in the previous two matrices now refer to actions Public may take, and High and Low to actions Government takes. Government moves first, but knows how Public will react (that is, whether the public will comply with a government program). Both Public's and Government's actions are fully observable. Suppose the true payoffs are as in Matrix 3, but Public believes that Matrix 2 represented the true payoffs. Public would then choose Left, no matter what Government chose. Government would be induced to choose High. If Public knew the true payoffs to their actions, it would choose Right - that is, to "comply" with a program of low government spending. 


\section{Matrix 3}

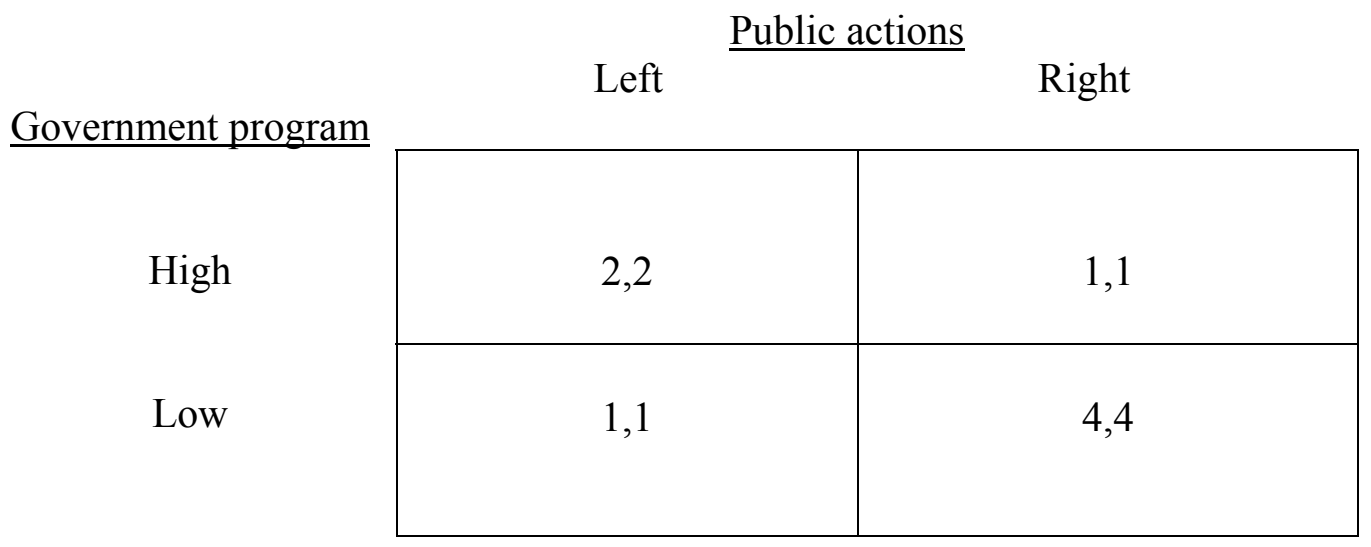

Consider, for example, a program of fiscal restraint that requires replacing government supply of goods (high government spending) with reliance on the private sector (low government spending) for supply. Success of the market solution requires public compliance. Public willingness to rely on the market rather than government is represented by Right rather than Left. Matrix 2 thus might represent public distrust of the market's ability to supply services, combined with an unwillingness to use the market. Public education thus means educating the public on the value of greater reliance on the market when there is a need to reduce the size of government, with Matrix 3 showing the value of the public acting in accordance with this view.

The functions of public discussion in revealing information to the government and in eliciting optimal public responses interact when public discussion enables the government to learn about the resources the public has. That is, public discussion can also play an important role in "educating the government" and identifying policy choices that are likely to be most efficient, or elicit the greatest ownership, when there are a number of options. (We leave it to the reader to combine the previous cases to demonstrate this formally.) Governments are rarely (if ever) fully informed of the effects of their policies on society, and there are endless examples of situations in which public discussion has made governments aware of adverse policy effects on certain groups of society and of the possible desirability of policy adjustments or compensating policy actions. This may be seen in the broad consultation that takes place among stakeholders and development partners during the process of preparing country strategy papers under the IMF and World Bank's poverty reduction initiative. For example, public discussion made governments aware of the regressive nature of local graduated taxes in Uganda and commune-level revenue-raising measures in Vietnam; of the effects of energy price liberalization on the livelihoods of fishing communities and low-paid casual laborers who were heavily affected by transportation costs in Mozambique; and of the scope for building ownership by addressing these public concerns. ${ }^{19}$ In addition to making

${ }^{19}$ See Robb (2003, Box 3). 
the government more aware of the effects of its policies, public discussion and participation sometimes identify resources that can be mobilized to pursue policy objectives more efficiently. $^{20}$

Yet another function of public discussion is to induce the government to make a greater commitment to a program and hence make it more credible that it will be carried through. One way to think of this is in terms of solving a time consistency problem. By taking publicly announced positions, the government changes the payoff structure associated with following a given policy in order to commit itself to a specific course of action.

For example, following a severe banking and currency crisis that led to near hyperinflation in early 1997, and in the context of negotiations with the IMF, the newly elected president of Bulgaria engaged in discussions with major political parties to forge a commitment to an economic program that included, inter alia, the introduction of a currency board. The commitment that resulted from the discussions was formalized in a "declaration" proclaiming the readiness of the major political parties to cooperate in fulfilling the agreement with the IMF. Elections in April 1997 shifted political power to a new majority, but the negotiated program continued to enjoy broad national ownership and was endorsed by the new parliament. ${ }^{21}$

\section{B. Case 2: Public uncertainty about government objectives}

We now focus on the issue of uncertainty about the government's objectives in the design of a program. That is, the government faces the problem of convincing the public that it is acting in the public's best interests, rather than having its own "agenda." Though the imperfect information issues discussed in the previous case may still be present (that is, where the government does not know the public's preferences, etc.), we assume these away in order to focus on the problem of the government making it credible to the public that it is acting in the public's best interests. We also continue to assume that the public is homogeneous (though not necessarily informed about what policies would maximize its welfare).

If the public believes that the government's preferences are not correlated with its own, then cheap talk may fail to convey information. Specifically, suppose that only Government knows the state of the economy, High or Low, which Public cannot observe, though it knows how the world works (that is, the true payoff matrix). Let us interpret More and Less as Public's action (say the level of wage demands). Public discussion (cheap talk) precedes any actions, where Government announces the state of the economy.

We now assume that the government's and the public's objectives can differ, which might reflect, for example, the weight Government puts on the reaction of global capital markets. Hence, suppose that instead of a payoff matrix such as Matrix 1, payoffs were

${ }^{20}$ See IMF (2003b)

${ }^{21}$ See IMF (2001). 
described by Matrix 4 (where Government's payoff is listed first). In this case, Government would like Public to play Less, no matter what the economic situation is. Hence, Government would like Public to believe that the state of the economy is Low. But Public, knowing the payoff matrix, knows Government has this incentive and so does not believe any Government announcement. "Talk" doesn't reveal Government's information because it is believed to have an objective other than maximization of social welfare - that is, to have different preferences than those of Public.

\section{Matrix 4}

\begin{tabular}{|c|c|c|}
\hline \multirow[b]{3}{*}{ State of economy } & \multicolumn{2}{|c|}{$\underline{\text { Public behavior }}$} \\
\hline & More & Less \\
\hline & & \\
\hline High & 1,3 & 5,1 \\
\hline Low & $-6,-3$ & 3,2 \\
\hline
\end{tabular}

However, even if the preferences of Government and Public are not perfectly correlated, information can be conveyed, but the type of message sent will be crucial in determining whether it is. Suppose, more realistically, that the state of the economy is not discrete as in Matrix 4, but is continuous. Suppose the payoffs are such that Government wants Public to believe that the state of the economy is somewhat worse than it really is (perhaps to give the incentive to accept lower wages as part of a "tough" program). For simplicity, suppose that if the state of the economy was $S$, Government would want Public to believe that the state was $S-x$, where this incentive is known to Public. One might think that cheap talk can convey no information here, since if Public discounts Government's announcement by some amount $y$ (that is, in response to an announcement of $S-x$, Public believes the state is $S-x+y$ ), Government will simply announce $S-x-y$.

A key result in the literature on cheap talk (Crawford and Sobel, 1982) is that imprecise messages can convey information as long as the incentive to distort information (in the example above, the amount $x$ by which Government wants to understate $S$ ) is not too large. That is, while a supposedly precise announcement of the state of the economy will not be believed, a "crude" announcement of the state of the economy, such as simply High or Low even when the state is continuous, will convey information.

This result has applications not only to cases in which Public is uncertain about Government's preferences, but also to cases in which Public knows that Government has 
different preferences, as long as the difference in preferences is not too large. In such situations, trying to get Public to comply with Government-recommended policies may be difficult when the choice set includes a continuum of policies (for example, different degrees of adjustment). However, presenting a choice between two discretely different alternatives may allow Government to credibly convey its superior information to a skeptical Public and thus gain acceptance of a program (roughly) tailored to the economic situation.

Such a situation is often encountered in IMF-supported programs - say, in fiscal tightening in response to the state of the economy. Let the state of the economy be continuous, with High and Low being very good or very bad states. The degree of possible fiscal tightening is also continuous, but with Government and Public differing on what is optimal in each state of the economy, owing to different discount rates for evaluating the trade-offs between current costs and future benefits. Both parties know that Public discounts the future more than does the Government. The Government has more information than the Public about the economic situation, both ex ante or ex post, and Public's support is required for fiscal tightening.

The differences in discount rates gives Government an incentive to overstate the seriousness of the economic situation by a discrete amount, and Public in turn is fully aware of Government's incentive. Suppose however that the Public is presented with a discrete choice - either government enacts no policy change or a specific amount of fiscal tightening. (One may think of the choice of either accepting or rejecting a specific IMF-supported program.) Accordingly, if the difference between the discount rates of Government and Public is not too large, Government's characterization of the economic situation (cheap talk) in combination with a choice restricted to two options can be successful in inducing Public to accept the proposed amount of fiscal tightening.

On the other hand, if the difference between Government and Public preferences is too large relative to the outcomes associated with the two choices, or - to return to the case where Public is uncertain about Government's preferences - if Public believes, rightly or wrongly, that the difference between Government's objectives and its own is sufficiently large (that is, that Government has too strong an incentive to mislead Public), then cheap talk cannot convey information.

When cheap talk provides no information, a government may need to use costly signals to convey information about its preferences. For example, a government whose objective is social welfare maximization may reveal this by taking actions that would not be mimicked by a government with other objectives because the latter finds them too costly. In formal terms, this is the issue of unobserved type, where one can think of two types of governments: a "good" or social-welfare-maximizing government; and a "bad" or non-socialwelfare-maximizing government. How can a government whose objective is social welfare maximization separate itself from one that has other objectives? For the "good" government to care (and for the "bad" government to have an incentive to try to masquerade as a "good" government), there must be a favorable response to the government, or its program, being perceived as in the public interest. Such a response is present when public support is required for programs to succeed and when the public complies only with programs that it either 
perceives to be associated with a good government (i.e., accepts because it is associated with a government it trusts) or is otherwise convinced to support.

Even when costly signals are used to reveal type, public discussion may play a role. Jamaica provides an interesting example in which the government established "good" credentials by taking the "costly" action of relinquishing IMF financial support and by employing transparency (public discussion) to win support for a homegrown macroeconomic program. ${ }^{22}$ Following three decades of heavy reliance on IMF support from the $1960 \mathrm{~s}$ through 1996, and while still facing very large adjustment problems, the government declared its "independence from the IMF," essentially rejecting the IMF's push for a devaluation to restore competitiveness along with workout measures for the financial sector. It opted instead for its own strategy of tight fiscal and monetary policies, guarantees for bank deposits and other liabilities, and a gradual approach to dealing with problem financial institutions. The government also made a strong commitment to transparency by agreeing to the publication of the IMF's fairly critical Public Information Notice following the 1997 Article IV consultation, ${ }^{23}$ along with subsequent IMF reports, and by issuing its own "commentaries" in which it emphasized both points of agreement and disagreement, thereby fostering public debate. Although it is difficult to judge whether the government's homegrown approach was more appropriate than the IMF's approach would have been in the absence of political commitment, it is clear that the government succeeded in building a strong degree of ownership for its homegrown program by putting its credibility on the line, incurring the cost of foregoing IMF credit, and fostering public discussion through its transparency policy.

When the government demonstrates its commitment to social welfare by choosing policies favored by the public, another problem may arise. What if the authorities believe that the public does not necessarily know what the best policy is? (The notion that a key function of public discussion is to educate the public about economic realities presumes that this is often the case.) A government that cares about social welfare faces a problem. Choosing the policy that the public says it prefers enables the government to demonstrate that it has ostensibly the same objectives as the public, but often at the cost of not maximizing the public's welfare! (This distinction is sometimes referred to as the difference between a government being responsive to citizens' expressed preferences and representative of public preferences. See Manin, Przeworski, and Stokes, 1999. This suggests that the only effective strategy that a "good" government can use to convince an uncertain public of its type is to "educate" the public that it is indeed advocating a "good" program - that is, a set of policies that is likely to generate attractive payoffs for the public relative to the payoffs associated with other courses of action (or inaction).

Genuine public discussion may serve a purpose here that cannot be achieved through simple announcement of policy or assertions about the economic realities on which policy is

${ }^{22}$ See the discussion in Independent Evaluation Office (2002), Chapter 12, pp. 198-200.

${ }^{23}$ PIN Number 97/28, October 2, 1997, available at www.imf.org. 
based. $^{24}$ The reason is that the requirement that positions be argued and justified to the public (either directly or by convincing experts who have credibility with the public) will eliminate some arguments as convincing rationale for policy. Exposing the (supposed) rationale for policy to the cold light of open public debate and scrutiny can often reveal whether or not the rationale is really social welfare maximization. (Fearon [1998] provides a nice discussion of this point.) Public debate can thus serve the purpose of demonstrating unbiasedness or revealing government type. The willingness itself to engage in public discussion may itself signal that the government's objective is maximization of social welfare, independent of any information that public discussion reveals. "Good" programs may face a lower cost of exposure to public discussion as they are more likely to survive public scrutiny. Public discussion may thus have different costs for different types of governments, or different types of programs. ${ }^{25}$

\section{Case 3: The public is heterogeneous}

In the third case, we focus on the role of public discussion when groups in society have conflicting interests. Conflict among members of a society is central to political economy in general (Drazen, 2000) and is a key problem in formulating reform and stabilization programs. Though the problem of the public having imperfect information about the government's preferences may be important here as well, we abstract from it to focus more exclusively on how public discussion might help hammer out an acceptable program when the public is heterogeneous. For the same reason, we also assume that the problem is not that the government must make credible that its objective is social welfare maximization. (Of course, there are interesting questions here - for example, the government must make credible that it is not too closely aligned with one interest group, such as the financial sector.)

Suppose the public is divided into three groups: the "general" public; and two SIGs (special interest groups) denoted "Green" and "Blue," who must consent for a program to be adopted. The general public is unorganized and lacks the power that the SIGs have to block an IMF-supported program. The government may be seen as maximizing the welfare of the general public. Here we focus on public discussion as revealing information about SIGs or coordinating their actions. It might also weaken their ability to achieve "selfish" aims by making it necessary for them to justify their demands, analogous to the discussion at the end of Section IV.B.

\footnotetext{
${ }^{24}$ In the examples of cheap talk, there is no real discussion or deliberation-the informed party sends a single message to the uninformed party. This is not unique to these examples. As Aumann and Hart (2003, p. 1619) point out, "Most formal models in this area [strategic information transmission] allow for at most one message from each player." They consider multistage cheap talk ("long cheap talk"), but the application of their results to public discussion is an issue yet to be explored.

${ }^{25}$ However, the signal is less than perfect, both because some regimes seem adverse to public discussion per se, and because public discussion may have adverse effects, as discussed in the next section.
} 
Getting the approval of SIGs may be seen as a coordination problem when it is not known exactly what they might be willing to concede (though their general preferences are known) or when there is initial disagreement about how the world works. Let's start with the simple reference case shown in Matrix 5. Each group must simultaneously choose an action, and each perceives that the payoffs depend as follows on the different combinations of actions. As in Matrix 4, public discussion - that is, an announcement by both Blue and Green precedes any actions. Here, cheap talk works as a coordination device because there is no real conflict of interest. If Blue announces that its interest is Down, then Green will clearly want to say Right, and we get to a better solution than we could expect without communication. In formal terms, Blue's message is both self-signaling and self-committing. It is self-signaling in that Blue wants to announce Down if and only if it is best. It is selfcommitting in that if Green believes Blue (which we just argued it should), the announcement creates the incentive for Blue to actually carry it out. Public discussion has the function of simply informing groups of where there may be common ground. If there is, then the program adopted will be superior to what would be adopted in the absence of public discussion.

\section{Matrix 5}

\begin{tabular}{l|c|c|}
\multicolumn{1}{c}{} & \multicolumn{1}{c}{ Left } & Rreen \\
Blue & \multicolumn{1}{c}{ Right } \\
\cline { 2 - 3 } Up & 3,3 & 1,1 \\
\cline { 2 - 3 } Down & 1,1 & 3,3 \\
\cline { 2 - 3 } & & \\
\hline
\end{tabular}

Of course, this example is too simple because there is no conflict of interest, only a problem of coordination. Farrell and Rabin (1996) point out that when the interests of SIGs are not so potentially well-aligned, cheap talk messages are less likely to be self-signaling or self-committing. A simple example is the well-known "prisoner's dilemma," where the payoffs are as in Matrix 6. Cheap talk precedes simultaneous action by the two groups. Here, for Blue it is optimal to choose Down for any choice Green makes, while for Green it is optimal to choose Right for any choice Blue will make. Cheap talk will not allow them to coordinate. ${ }^{26}$ Messages are not self-committing. Though one may argue that repeated play of the game by the same players may lead to a cooperative solution, and that is what is seen in

\footnotetext{
${ }^{26}$ It is argued that "players" in situations like this often play "cooperatively" and that communication may have a coordinating effect. See footnote 14 in Farrell and Rabin (1996).
} 
experimental studies (see the previous footnote), the basic message is clear: if SIGs see their interests as sufficiently in conflict in relation to a stabilization program, public discussion in the sense of simply exchanging information may have limited value.

\section{Matrix 6}

\begin{tabular}{|c|c|c|}
\hline & \multicolumn{2}{|c|}{ Green } \\
\hline & Left & Right \\
\hline Up & 7,7 & 4,8 \\
\hline Down & 8,4 & 5,5 \\
\hline
\end{tabular}

An argument put forward in discussing Case 2 is relevant here as well. Public discussion that requires interest groups to justify their demands may eliminate some claims because they are unjustifiable in a setting of genuine, open discussion. Forums to elicit public input and reaction to proposed programs may be effective in revealing useful information only to the extent that they are not too "warm and fuzzy." More exactly, eliciting credible information about preferences of groups is not easy once the groups know they have strongly conflicting objectives.

The situation is somewhat different when government and IMF actions (including actions other than public discussion) can influence the payoffs that SIGs associate with different outcomes. When the interaction is among SIGs, but the authorities can change the payoff matrix, they could, for example, transform a prisoner's dilemma as in Matrix 6 to a coordination game as in Matrix 5. More concretely, the ability to modify proposed programs and "sweeten the deal" for interest groups can be seen in this light. In the process of drafting legislation that can get through national parliaments, this is common - amendments being added to legislation to win the support of specific legislators or groups. IMF-supported programs are often structured with similar political constraints in mind. When the ownership problem is one of getting the political consent of powerful groups, building ownership may in fact be identified with cases in which the cooperative outcome is made credible, as distinct from cases in which it is not. We return to this issue in Section VI below. 


\section{Public discussion and democratic values}

A very different, but important point is that public discussion can be instrumental in strengthening democratic values, independent of the outcome of specific discussions. That is, encouraging public discussion on one type of issue may increase the likelihood that public discussion is used in other contexts as well. If the political culture is such that government decisions are not generally subjected to public discussion - that is, if the paradigm of deliberative democracy is not well-developed - then public discussion of economic policy can have a valuable learning effect. This may well be the case in new democracies. ${ }^{27}$ An outside body, such as the IMF, may be effective in fostering such a discussion in countries where this tradition is weak or nonexistent.

\section{Drawbacks of Public Discussion}

Public discussion may have significant drawbacks as well. Przeworski (1998) and Stokes (1998) have argued, for example, that when public discussion is followed by voting, lobbyists and interest groups may have incentives to mislead voters in the process of public discussion, such that voting actually becomes less informed rather than more informed. The possibility that public discussion could cause people to be misled by SIGs is also present in the context of program design, but we don't think that this is the central problem of public discussion of IMF-supported programs. In fact, the key drawbacks of public discussion in the context of adopting an IMF-supported program may be quite different than the drawbacks of discussion as a prelude to voting.

In the case of public acceptance of an IMF-supported program, one problem is that public discussion may essentially give interest groups more veto power over a proposed program, or a heightened awareness of adverse implications and stronger incentives to use their veto power. To the extent that public discussion simply informs governments about the public's true preferences, as in Case 1 (where the public as a whole is seen as homogeneous), discussion improves program design. But, when the public includes strong SIGs whose interests are not those of the general public (Case 3), there is a danger that a policymaking process that gives them too large a voice will result in a program that does not serve the public good. Social welfare may thus be higher when the authorities make "take-it-or-leaveit" offers, rather than allowing public discussion to give too much influence to SIGs. This has been a criticism, for example, of giving NGOs a large say in program design, where the implicit assumption is that their interests do not necessarily reflect the broader public interest.

Second, public discussion can be time consuming and may slow the process of shaping a program. This is potentially quite a serious problem when the economy is in crisis

${ }^{27}$ Brender and Drazen (2004) find that political deficit cycles are far stronger in new democracies than in established democracies and suggest that lack of availability and analysis of information about the fiscal process may lead to this observed difference. They also find that as a country gains experience with democracy, the political cycle disappears. See also Akhmedov and Zhuravskaya (2003) for evidence of this effect in Russia after the transition to democracy. 
and a program needs to be put in place quickly. The problem of having exactly the "right amount" of discussion is obviously a very difficult one that probably is not conducive to any general rules. The right amount of public discussion will be very much situation specific.

Third, since programs may go through a lot of changes, making discussion public will involve groups (and the government) in espousing positions that may subsequently be rejected and even become viewed as incorrect. The costs of being put in such a situation may induce groups to refrain from putting forward public positions at all, or to take positions in public that differ from the positions they would put forward in private. Hence, public discussion could actually greatly hinder information transmission relative to more confidential means of discussion.

Fourth, since the discussion of IMF-supported programs tends to focus attention on a country's bad economic situation, making information public may in itself make the situation even worse. Some types of information may "spook" financial markets and lead to major capital outflows, making it even harder to design a successful program. This appears to be the main concern expressed in relevant IMF Board meetings by those Executive Directors who oppose full "transparency" - that is, who oppose full revelation of the IMF's information and/or concerns about countries. ${ }^{28}$

None of these concerns is easy to address, since they are all both genuine and situation specific (and hence hard to address in any generality). They should not be taken as arguments against public discussion per se, but only as cautions in considering how public discussion of a program should be structured.

\section{The Design OF IMF-Supported Programs}

The importance of national ownership is clearly recognized in the principles that govern the design of IMF-supported programs. The IMF's Guidelines on Conditionality, ${ }^{29}$ as revised in September 2002, indicate that national authorities have the lead role in shaping program documents $^{30}$ and that the IMF should encourage countries to build broad support for sound policies. Moreover, in association with the Guidelines, the set of general operational instructions provided to IMF staff engaged in program design is based on five key principles: (i) "national ownership of reform programs; (ii) parsimony in program conditions; (iii) tailoring of programs to a member's circumstances; (iv) effective coordination with other multilateral institutions; and (v) clarity in the specification of conditions." 31

In moving from principles to procedures, the operational instructions emphasize that IMF staff "should seek proposals from national authorities at an early stage in the policy

${ }^{28}$ See IMF (2003c).

${ }^{29}$ IMF (2002).

${ }^{30}$ There is no requirement that country authorities draft program documents, but rather the directive that the IMF staff be responsive when the authorities desire a greater role in the drafting process.

${ }^{31}$ IMF (2003a), paragraph 2. 
dialogue." They also stress that IMF staff "should encourage the authorities to engage in a transparent participatory process in developing a policy framework, and should continue to be prepared to assist the authorities in this process by giving seminars, meeting with various interest or political groups (parliamentary committees, trade unions, business groups, etc.) and by being available to the media...[while being mindful] of the authorities' views on staff contact with domestic groups...." In addition, the operational guidance note stresses that documents prepared by the IMF staff in the course of briefing the IMF's management and reporting formally to the Executive Board should assess the challenges to broad ownership, including key capacity weaknesses and issues relating to political structures. It also clarifies the principle of parsimony in program conditions: performance criteria, prior actions, and other program conditions must be limited to those that, if excluded, "would seriously threaten the achievement of program goals or the IMF's ability to monitor implementation., 32

The emphasis on ownership and transparent participatory processes in the recently revised IMF Guidelines and guidance notes is consistent with the position of the IMF's Independent Evaluation Office (IEO). In its evaluation of cases in which IMF-supported programs have not succeeded in weaning countries off the need for official financial support, the IEO concluded that the extent and structure of program conditions was much less important than securing an underlying commitment to core policy adjustments. It consistently suggested that the aim in program design should be to move as quickly as possible to a situation in which the core elements of a program are subject to a policy debate within the country's own policymaking institutions, and that the IMF staff should actively seek to present policy options, analyze the trade-offs between them, and encourage open debate on the alternatives. ${ }^{33}$

These recommendations are supported by case studies of Pakistan, the Philippines, and Senegal, where lack of political commitment was a major factor in program failures, and of Morocco and Jamaica, where a "real difference seems to have been made by strong domestic ownership." 34

In the case of Senegal, for example, despite significant progress during the 1980s in transforming the economy away from excessive state intervention, roughly one-third of the measures envisioned under World Bank structural adjustment loans were not implemented as scheduled. These measures were concentrated in areas such as labor regulations, where there was strong opposition from vested interests, and where the government apparently made little prior effort to generate public discussion and reach consensus on key issues. Senegal's failure to pursue adequate public discussion also contributed to a lack of clarity and progress in its efforts to restructure the groundnut sector during the $1980 \mathrm{~s}$, which was a source of income for the majority of the rural population and a key sector in the effort to reduce poverty. ${ }^{35}$

\footnotetext{
${ }^{32}$ IMF (2003a), paragraphs 6 and 7.

${ }^{33}$ Independent Evaluation Office (2002), pp. 12-14.

${ }^{34}$ Independent Evaluation Office (2002), pp. 16-18.

${ }^{35}$ Independent Evaluation Office (2002), Chapter 11, which cites reports of the World Bank's Operational Evaluation Department.
} 
By contrast, in Morocco, where evaluation reports have found no major differences in the approach to economic program design from that followed in other countries with IMFsupported programs, "increasing transparency in putting information and policies out for public discussion ... appears to have helped develop a broader consensus [for reform]" and was a critical factor in weaning the country from prolonged reliance on IMF loans. ${ }^{36}$

Despite the heightened awareness of the importance of country ownership and the relevance of public discussion ("participation"), most references to public discussion or participation in IMF documents are cast in broad terms, with little or no explicit recognition of the different functions that public discussion can serve, and little or no explicit focus on which specific functions it can usefully serve in specific circumstances. Of course, IMF staff rarely engage in public discussion without advanced brainstorming or other forms of preparation, which often is not reflected in any written documents; and it would be misleading to suggest that IMF staff engage in public discussion without a fairly clear implicit sense of what they are trying to achieve. Nevertheless, the effectiveness of public discussion in building and assessing ownership of IMF-supported programs might be significantly enhanced by greater awareness of the range of functions that public discussion can serve and a more systematic focus on strategies for engaging in public discussion in specific circumstances.

Although public discussion can enhance ownership in various ways, it would be misleading to suggest that discussion alone can induce complete ownership of IMFsupported programs. Many of the countries that seek to negotiate IMF-supported programs require fiscal adjustment to restore and maintain macroeconomic stability. Because such adjustment necessarily leaves some interest groups worse off in the short run, complete ownership of the fiscal components of IMF-supported programs is generally difficult to achieve. Nevertheless, public discussion in this context-with sufficient efforts to keep it well-focused - can be particularly important for building ownership by educating the public about the overall economy-wide benefits of fiscal adjustment in the short run, about prospects that the benefits will be widely shared over the medium run, and about the gains from a cooperative solution that elicits financial support from the IMF and other sources. It can also contribute to building ownership by helping governments find the type of cooperative solution or policy mix that stands the best chance of sustaining political support - particularly so when the IMF gives policymakers broad freedom to design the specific details of the fiscal adjustment effort. In this context, it may be very important for the IMF to refrain from pressuring governments to adopt policies that are appealing on efficiency grounds but typically provoke strong public resentment, such as raising or eliminating ceilings on the price of necessities.

Despite these various ways that public discussion can enhance ownership of fiscal adjustment policies, it cannot overcome the fact that various interest groups may continue to have incentives to seek to benefit in the short run by undermining the fiscal adjustment effort.

${ }^{36}$ Independent Evaluation Office (2002), Chapter 12, page 196. 
This is why the effectiveness of many IMF-supported programs depends critically on appropriate prior conditions, fiscal performance criteria, and the phased provision of IMF credit. $^{37}$

Although public discussion on its own cannot achieve complete ownership of programs for countries in which the restoration of macroeconomic stability requires fiscal adjustment, IMF-supported programs need not be (and generally are not) limited to policy actions that impose short-run costs. Indeed, one approach to enhancing the overall ownership of IMF-supported programs is to try to counteract conditions that impose short-run costs with conditions that the public correctly perceives to convey major benefits. In this context, public discussion - through many of the functions it can serve (e.g., eliciting information about what the public wants, educating the public, educating the government and the IMF, revealing that the government is indeed oriented toward maximizing social welfare, leading heterogeneous interests to a cooperative solution) - may well be able to strengthen the overall ownership of programs by building virtually complete support for various types of structural measures (e.g., clarification of property rights, strengthening of tax-collection mechanisms and accounting standards) that do not impose costs on any powerful interest groups, at least in the context of a "good government" where there is little or no inherent incentive to oppose important growth-enhancing structural reforms.

\section{Conclusions}

There has been growing recognition in recent years that the effectiveness of IMFsupported programs depends importantly on the degree of country ownership, and that ownership can be promoted by seeking to broaden and deepen the base of support for sound policies among a country's domestic interest groups. These perceptions are reflected both in the September 2002 revision of the IMF's Guidelines for Conditionality (IMF, 2002) and in the international community's decision to link debt-relief for highly indebted poor countries (HIPCs) to the formulation of poverty reduction strategies through processes that involve the broad participation of stakeholders.

This paper has focused on public discussion as one potentially important vehicle for enhancing program ownership, where the functions of public discussion are summarized at the beginning of Section III. The motivation comes from our sense that economists do not yet have a very clear understanding of the various channels through which public discussion can work, or of the types of circumstances in which public discussion can be effective. This lack of understanding has contributed to the view-held in some quarters - that public discussion

37 The time dimension of IMF-supported programs provides an interesting direction for further thought on the role of public discussion. In particular, given that the IMF is often criticized for being too willing to waive or modify performance criteria (not being a sufficiently "tough cop"), it is interesting to consider whether public discussion that starts at the time of the initial request for financing can strengthen compliance with program conditions by making it more credible that the IMF will say "no" on test dates for subsequent installments of financing when governments breach the conditions established at the outset of their programs. 
strengthens ownership primarily by leading counterproductively to the adoption of weaker programs. More seriously, failure to appreciate and distinguish between the range of functions that public discussion can serve and the circumstances that determine its effectiveness or ineffectiveness in those functions implies that country governments and the IMF may not be exploiting the potential of public discussion in the most effective ways. A better understanding of public discussion can contribute to the effort to design strong programs that can command broad country ownership. We have argued, primarily by way of example in illustrating the functions that public discussion may serve, that it can in fact be an important tool in raising the probability of program success.

It would be wishful thinking, however, to suggest that public discussion alone can lead to complete ownership of a program that imposes significant costs in the short-run. Those interest groups that stand to incur the short-run costs pose significant risks to the adjustment effort in the absence of appropriately structured conditionality that provides financial incentives for countries to remain in compliance with their policy commitments. Moreover, as we argued in Section V, there are drawbacks to public discussion, especially in the presence of strong interest groups.

By contrast, public discussion may be able to achieve virtually complete ownership of growth-enhancing structural reforms that impose no significant costs in either the short run or the longer run. Accordingly, public discussion has the potential to contribute importantly to growth by inducing the public to want to pursue more growth-enhancing structural reforms as parts of their policy programs. In principle, program conditionality is not necessary for achieving compliance when there is complete ownership of reforms, although in practice it may be useful for spurring progress.

Ironically, the efforts that the IMF has made to build program ownership by streamlining conditionality in recent years appear to have shifted the focus of IMF-supported programs away from the types of growth-enhancing structural policies on which ownership would seem relatively easy to build. We attribute this in part to the limited attention that economists have paid to the concept of ownership and to the process of building ownership through public discussion. 


\section{REFERENCES}

Akhmedov, A. and E. Zhuravskaya, 2003, "Opportunistic Political Cycles: Test in a Young Democracy Setting," Working Paper.

Aumann, R. and S. Hart, 2003, “Long Cheap Talk,” Econometrica, Vol. 71, pp. 1619-60.

Boughton, J. and A. Mourmouras, 2002, "Is Policy Ownership An Operational Concept?" IMF Working Paper 02/72.

Brender, A. and A. Drazen, 2004, "Political Budget Cycles in New versus Established Democracies," NBER Working Paper 10539.

Crawford, V. and J. Sobel, 1982, "Strategic Information Transmission," Econometrica, Vol. 50, pp. 1431-51.

Drazen, A., 2000, Political Economy in Macroeconomics (Princeton, NJ: Princeton University Press). , 2002, "Conditionality and Ownership in IMF Lending: A Political Economy Approach,” IMF Staff Papers 49 (Special Issue).

Elster, J., ed., 1998a, Deliberative Democracy (Cambridge, UK: Cambridge University Press). , 1998b, "Introduction," in Elster, J., ed., Deliberative Democracy.

Farrell, J. and M. Rabin, 1996, "Cheap Talk," Journal of Economic Perspectives, Vol. 10, pp. 103-18.

Fearon, J., 1998, "Deliberation as Discussion,” in Elster, J., ed., Deliberative Democracy.

Habermas, J., 1987, Theory of Communicative Action (Boston: Beacon Press).

Independent Evaluation Office, 2002, Evaluation of the Prolonged Use of Fund Resources (Washington: International Monetary Fund), available at www.imf.org.

International Monetary Fund, 2001, "Strengthening Country Ownership of Fund-Supported Programs," December 5, available at www.imf.org.

— , 2002, “Guidelines on Conditionality," September 25, available at www.imf.org.

— , 2003a, "Operational Guidance on the New Conditionality Guidelines," May 8, available at www.imf.org.

— , 2003b, “Chad: Poverty Reduction Strategy Paper,” IMF Country Report No. 03/209 (July), available at www.imf.org. 
— , 2003c, "IMF Reviews the Fund's Transparency Policy-Issues and Next Steps," Public Information Notice (PIN) No. 03/122 (October 10), available at www.imf.org.

Manin, B., A. Przeworski, and S.C. Stokes, 1999, "Elections and Representation," in A. Przeworski, S.C. Stokes, and B. Manin, eds., Democracy, Accountability, and Representation (Cambridge, UK: Cambridge University Press).

Mussa, M. and M. Savastano, 2000, “The IMF Approach to Economic Stabilization,” NBER Macroeconomics Annual 1999 (Cambridge: MIT Press), pp. 79-122.

Przeworski, A., 1998, "Deliberation and Ideological Domination," in Elster, J., ed., Deliberative Democracy.

Robb, C.M., 2003, "Poverty and Social Impact Analysis_-Linking Macroeconomic Policies to Poverty Outcomes: Summary of Early Experiences," IMF Working Paper 03/43.

Stokes, S.C., 1998, "Pathologies of Deliberation," in Elster, J., ed., Deliberative Democracy.

Wimmer, A. I. de Soysa, and C. Wagner, 2002, "Political Science Tools for Assessing Feasibility and Sustainability of Reforms," paper prepared for the Independent Evaluation Office (Washington: International Monetary Fund). 